\title{
La Doctrina Social Católica y la economía de los EE. UU.
}

\section{Por Gonzalo Higuera}

El pasado noviembre, con motivo de la celebración en Washington de su reunión plenaria, la Conferencia Episcopal de los EE.UU. de América difundió en primer borrador el proyecto de una carta pastoral que se espera quede aprobada definitivamente para dentro de un año. Se titula el borrador: Catholic Social Teaching and the U. S. Economy.

\section{Motivaciones}

Los motivos impulsores para redactar el documento muy conveniente para algunos, e imprescindible para otros, han sido varios. Tres son los principales.

En primer lugar encontramos como raíz motivadora la carta pastoral de 1980 relativa al comunismo marxista. No se produjeron entonces grandes dudas en cuanto a contenidos y valoración éticas. Sin embargo -y nos parece que muy acertadamente- un grupo de obispos, al que siguieron otros de sacerdotes, religiosos, economistas, políticos e incluso miembros de otras confesiones religiosas, pidió entonces con fuerza la redacción de otra carta pastoral valorativa del capitalismo. Los documentos sociales católicos normalmente venían valorando ambos extremos.

En segundo lugar, para salir al paso de la posible, aunque falsa identificación, de los principios sociales cristianos "con nuestra estructura económica (la de EE. UU.), Esa identificación debilita nuestra credibilidad y hace al comunismo atractivo para el Tercer Mundo".

En tercer lugar, para que con el nuevo documento se pusieran de relieve las reales injusticias económicas de los EE. UU. desde una perspectiva ética y la consiguiente obligación de subsanarlas dando ejemplo 
porque - se indicaba entonces- "un estilo de vida, sobrio y responsable, sería más eficaz que la misma propaganda antimarxista para disuadir el paso o la simpatía hacia el comunismo". La fuerza del ejemplo.

Otros motivos son de menos importancia o fácilmente reducibles a los tres anotados.

\section{Cronología}

Desde el primer instante del proyecto hasta el momento de la aprobación definitiva van a transcurrir ${ }_{f}$ justamente, cinco años. A continuación los principales hitos:

1980.-En noviembre se acepta la propuesta que pide la redacción de una carta pastoral a nivel nacional sobre "La enseñanza social católica y la economía de los EE. UU."

Se nombra una comisión "ad hoc" que trabaja con ahínco y concluye la redacción del primer borrador en un plazo relativamente corto.

De momento, sin embargo, queda aparcado: 1) por la prioridad otorgada a otro borrador encargado en la misma Asamblea Plenaria sobre el desarme y la paz: "The challenge of the peace" (El desafío de la paz) que vio la luz el 3 de mayo de 1982; y 2) por no interferir en el período de campaña para la elección presidencial en el que se podría manejar el proyecto como instrumento político a favor o en contra de determinada postura electoral. A la vista de lo ocurrido durante la campaña en temas como el aborto, etc.. los obispos se muestran satisfechos por el aplazamiento de la difusión del borrador y ven "a posteriori" que decidieron acertadamente.

1984.-Al día siguiente de haber sido elegido el Presidente -7 de noviembre - se envía por correo una copia (120 o 136 páginas si incluimos notas y anexos) a cada uno de los 290 obispos norteamericanos. $Y$ el día 9 - dos antes de comenzar la reunión plenaria- se entregan ejemplares a todos los medios de comunicación social, entidades, particulares, etc., que en seguida acusan recibo con abundantes editoriales; artículos, entrevistas, reproducciones más o menos extensas, comentarios, etc.

En la Plenaria se hacen las primeras preguntas aclaratorias aunque no hay discusión formal. Y se abre un plazo hasta el 15 de febrero de 1985 para pulsar las reacciones y comentarios de todo tipo que produzca el borrador.

1985.-Tres momentos principales ya planificados:

a) De marzo a mayo, la Comisión redactará el segundo borrador integrando las enmiendas de los obispos, respuestas recibidas y consideraciones hechas desde diversos ángulos.

b) El segundo borrador se presentará en junio a la Asamblea Plenaria reunida en Collegeville (Minn.) de la que saldrá el tercer borrador que se remitirá durante el verano a los obispos para un postrer estudio. 
c) En la Asamblea Plenaria de noviembre habrá ocasión para las últin mas enmiendas, tendrá lugar la discusión final y se celebrerá la votación que convertirá todo el trabajo realizado en documento pastoral definitivo acerca de "La enseñanza social católica y la economía de los EE. UU."

\section{Metodología}

Le dedicamos un apartado porque nos parece ejemplar y, además de práctica, susceptible de adaptable imitación.

Aparte de lo indicado en la cronología, conviene explicitar que a la vista de los positivos resultados que se obtuvieron, la Comisión redactora ha seguido la misma metodología que se utilizó para la redacción de la pastoral sobre la paz.

Un primer borrador a cargo de la Comisión redactora, presidida por el Arzobispo de Milwaukee, Rembert G. WEEKLAND (1).

La Comisión solicita y oye todo tipo de pareceres de distintas ideologías, posiciones sindicales, económicas, políticas, éticas, religiosas, sin la menor cortapisa. El criterio selectivo que ocupa el primer plano es la competencia de los llamados de manera que no se eluden la recepción y escucha de sopesados pareceres aunque pudieran saberse a priori muy divergentes. Es ejemplar la sincera colaboración prestada, también sin mayores reparos ideológicos, por muy contrarios o indiferentes que fueran hacia el catolicismo. Se invirtieron en esta labor dieciséis sesiones que supusieron veintitrés jornadas durante las que hicieron acto de presencia ante la comisión redactora centenary medio de tales personalidam des especializadas, a las que hay que unir los consultores y la plantilla técnica de la propia Comisión que, salvo omisión involuntaria, alcanzan la docena.

Radactado el borrador con esa polifacética y competente colaboración no se hace ningún misterio de él y se da a la publicidad: obispos en primer lugar y medios de comunicación normales y especializados. Todas las ideologías políticas, religiosas y económicas de los Estados Unidos conocen y pueden poner reparos y críticas públicas al borrador.

(1) Otros miembros de la Comisión son: el arzobispo Thomas DONNELLAN de Atlanta (Ga.); el obispo George SPELTZ de St. Cloud (Minn.); William WEIGEND, obispo de Salt Lake City y el obispo auxiliar Peter ROSAZZA de Hartford (Conn.). A este útimo se debió, en 1980 la iniciativa de redactar una carta pastoral sobre el tema económico.

La Comisión ha gozado del apoyo moral, algunas veces extraordinario y siempre ejemplar de los tres centenares de obispos católicos que integran la Conferencia Norteamericana. Nos permitimos, sin embargo, destacar tres nombres: el de James A. MALONE, arzobispo de Youngstown (Ohio) actual presidente de la Conferencia Norteamericana; el de John $\rfloor$, O'CONNOR, arzobispo de Nueva York y el de Joseph BERNARDIN, arzobispo de Chicago que, desde su posición más bien conșervadora, ha prestado un gran aliento y apoyo a la redacción de borrador sobre la economía, después de la publicación de la pastoral sobre las armas nucleares, el desarme y la paz.

El número de colaboradores periciales y expertos alcanza los 125. Sus nombres constan. singularmente y con agradecimiento en el Apéndice l, al final del borrador, así como en el Apéndice ll se mencionan los nombres de los Consultores y el de los cuatro integrantes del equipo de la Comisión. 
Estas críticas son recogidas cuidadosamente para su detenido estudio antes de la segunda redacción.

Esto en cuanto a la metodología que podríamos denominar extrínseca. Porque en cuanto a la interna la han movido dos finalidades: a) Facilitar a los fieles de la Iglesia Católica de los EE. UU. una guía ética para obrar orientadamente en materias económicas. b) Que la voz de la misma Iglesia Católica, por medio de sus obispos se dejara oír en el debate público acerca de la política económica de los EE. UU. juntándose y colaborando con el resto de las opiniones y pareceres.

Para lograr este doble fin se ha tenido presente como hilo conductor, a lo largo de toda la redacción, una pregunta a la que dar respuesta: "¿Qué realiza o debe realizar la política económica en favor de los pobres y miembros necesitados de la comunidad humana?" Pregunta que, a su vez, metodológicamente, se desdobla en el siguiente par: "¿Qué se hace por el pueblo? ¿Qué hace al pueblo la política económica actual?"

El norte que orientará las respuestas no es otro que "la dignidad de la persona humana como criterio con el que deben medirse todos los aspectos de la vida económica. Dignidad que sólo puede realizarse en relación y solidaridad con los demás".

Y todavía un poco más adelante otro toque metodológico para el desarrollo doctrinal del borrador que toma "como base lo que hoy se conoce con la expresión 'opción preferencial por los pobres'. Esta opción - deducida de la Sagrada Escritura- desafía a la Iglesia de nuestro tiempo para que hable pory en nombre de aquellos que se encuentran en la indefensión y en la pobreza".

\section{Esquema}

El proyecto en primer borrador es extenso (2). Tememos que por ese carácter provisional no se publique ninguna traducción hasta llegar a la redacción definitiva (3). Sin embargo, se puede por lo menos dar una idea de cómo se halla construido el armazón ideológico aunque nunca podrá agotarse, ni siquiera de forma aproximada, la riqueza de contenidos.

INTRODUCCION.-La Iglesia y la Economía. Por qué hablamos.

PRIMERA PARTE.-Fundamentos biblicos y teológicos.

(2) Manejamos el original tal y como le reproduce la revista norteamericana Origins, n. ${ }^{\circ} 23$ / 24 del 15 de noviembre, 14 (1984) 337-383. Son, pues, 46 páginas en apretados caracteres.

(3) Al menos hasta el momento en que estamos redactando estas líneas no tenemos noticia de ninguna traducción del texto integro en lengua espafiola. Postura por otra parte explicable dado el carácter provisional del documento. Mientras tanto, estimamos como actitud de servicio para con nuestros lectores el acercarles lo más posible al borrador, sintetizando esquemáticamente la totalidad del contenido. 


\section{Visión cristiana de la vida económica}

La dignidad de la persona humana es el critërio con el que hay que medir todos los aspectos de la vida económica. Sólo realizable en relación y solidaridad con los demás.

\section{A. Perspectivas bíblicas y vida económica}

1. Creación, Alianza y Comunidad: base de reflexión para la justicia económica y social.

2. El primado de la justicia: relación con el prójimo.

3. Riqueza y pobreza: la riqueza es un mal cuando de tal manera domina a la persona que se ha convertido en un ídolo que aparta de Dios y/o ciega a la persona para ver al prójimo necesitado y que sufre. OPCION PREFERENCIAL POR LOS POBRES.

4. Comunidad y justicia social.

B. Vivir como discipulos hoy: de la Biblia a la ética económica, pasando por la tradicional doctrina social con la reflexión acerca de la vida económica.

\section{Normas éticas para la vida económica}

Las estructuras económicas no se pueden evaluar sólo por su eficiencia productiva y la cantidad de bienes o servicios que prestan. Tenemos que preguntar ¿permiten esas estructuras la participación a todas las personas que las integran y que producen?...

A. Derechos humanos: el mínimo de condiciones para la vida de comunidad.

Autorrealización en el trabajo; satisfacer las necesidades materiales y unir y solidarizarse con la familia, la nación y la comunidad mundial.

Exitos y fracasos e injusticias.

“.. todas las personas tienen derechos en la esfera económica y nuestra sociedad tiene la obligación moral de dar los pasos necesarios para asegurar que ninguno de nosotros padezca hambre, carezca de vivienda, esté parado o de cualquier otra forma se le niegue lo necesario para vivir con dignidad". Tenemos democracia política y ha llegado el tiempo de pasar a la democracia económica.

B. Justicia, poder y prioridades institucionales.

La Justicia reclama que se establezcan unos mínimos niveles de participación para todas las personas de la comunidad.

1. Se da fuerte presunción de desigualdades de rentas y patrimonio cuando tenemos en nuestra comunidad personas pobres, hambrientas o sin techo.

2. Una desigual distribución de ingresos, de patrimonio, educación, oportunidades de trabajo o de otros bienes económicos por motivos raciales, de sexo o de otros criterios arbitrarios, no pueden justificarse. 
Tres principios prioritarios deben configurar la política económica y las instituciones tanto nacionales como internacionales.

1. La prioridad suprema está en satisfacer las necesidades básicas de los pobres.

2. El aumento de participación de los marginados tiene prioridad sobre la conservación de las concentraciones privilegiadas de poder, riqueza y rentas.

3. Deben ser objetivos prioritarios en el empleo del dinero, talentos y energías el atender a las necesidades humanas y al aumento de la participación.

C. Responsabilidades y derechos de los diversos Agentes e Instituciones económicas.

1. Trabajadores y sindicatos (empleo, salario justo y negociación colectiva).

2. Ejecutivos, inversionistas, hombres de empresa, bancos.

3. Ciudadanos y Gobierno: caridad y subsidiariedad.

4. Agentes de la economía transnacional e internacional (multinacionales).

5. Consumidores y acumuladores de riquezas (moral del subdesarrollo).

6. La Iglesia (como cuerpo e individualmente).

SEGUNDA PARTE.-Aplicaciones concretas de política económica (4)

\section{Empleo}

La prioridad más urgente es la creación de nuevos puestos de trabajo con retribución justa y en condiciones laborales adecuadas.

A. Desvalores y efectos del desempleo: enormes, los niveles actuales moralmente injustificables.

B. Causas y remedios.

C. Objetivos políticos: reducir el paro al 3-4 por ciento; creación de puestos de trabajo directamente dirigidos a los estructuralmente parados, etc.

\section{Pobreza}

Más del 15 por ciento de la población norteamericana se halla por debajo del nivel oficial de pobreza: escándalo social y moral que no puede ignorarse.

(4) En esta parte, el borrador escoge como botones de muestra cinco situaciones socioeconómicas de tos EE. UU, tanto "ad intra" (nacionales) como "ad extra" (en su relación internacional) muy reales las cinco y analizadas estadisticamente. La selección se ha hecho por estimarlos como centrales (y creemos que en verdad lo son). Inmediatamente el borrador las aplica. 
A. Factores institucionales: discriminación racial y étnica; feminización de la pobreza; distribución de rentas y patrimonios.

B. Normas operativas: implantación de una economía saneada que provea oportunidad de empleo para todos; remover barreras que impidan el pleno e indiscriminado empleo a mujeres y minorías; reformas en el sistema fiscal; protección y programas para criar, educar y cuidar los niños.

C. Reformas para el bienestar social: asistencia y ayuda.

\section{Agricultura y alimentación}

En este primer borrador esta sección es laguna que rellenará la segunda redacción.

V1. Un nuevo experimento norteamericano: colaboración para perfilar la futura economía

En cooperación y colaboración que renueve el sentido de solidaridad, participación y corresponsabilidad.

A. Cooperación con las industrias privadas y particulares.

B. Cooperación a nivel local y regional.

C. Cooperación en el desarrollo de la política económica nacional.

D. Cooperación internacional.

VII. La economía de los Estados Unidos y la economía mundial: complejidad, desafio y decisiones

A. Relaciones económicas en un mundo interdependiente.

B. Importancia de la enseñanza social católica.

C. Politica de los EE. UU. acerca del desarrollo internacional: una crítica.

$D$. LOS EE. UU. y los países en vias de desarrollo. Decisiones constructivas: relaciones comerciales; deuda con el Tercer Mundo; ayuda al desarrollo; inversión privada en el extranjero.

E. Responsabilidad de los EE. UU. para con las formas delorden político internacional.

CONCLUSION - Llamamiento a la totalidad y a la santidad. Actividad y ocio. Trabajo y oración. 
La escueta lectura del esquemático índice que precede - aun deficiente y muy incompletamente pergeñado- es bastante expresiva para poder concluir que el documento, ya en su primer borrador, es valiente y no elude la previsible colisión con mentalidades socio-económicas enraizadas y muy queridas por grandes sectores económicos y sociales de los EE. UU. Pero lo puede hacery lo hace posible sin políticas, desde la independencia que proveen los principios éticos y morales. Por eso tampoco elude las autocríticas y denuncias de situaciones concretas como las seleccionadas. El documento en su análisis está respaldado por una razón - la humana - y por una fe - la cristiano-católica- asi de sencillamente. Por eso, y a través de eso, ve, juzga y deduce, pide y exige que hay que actuar en la dirección y sentidos redescubiertos para las situaciones concretas de EE. UU. y en sus relaciones socio-económicas con el resto de los países y de la entera comunidad internacional. Desde el primer borrador y por muchas esquinas que se suavicen en ulteriores redacciones, no hay duda que resultará un documento profético en su última redacción.

\section{Valor doctrinal del documento}

Con la metodología que se viene siguiendo en la redacción del proyecto y los contenidos que trata podría parecer superfluo este apartado (5). En efecto, deducido de las fundamentales exigencias de una moral a la par humanista y religiosa; inducido de las concretas situaciones injustas y, por lo tanto, inmorales, no cabe duda alguna del valor doctrinal y de la obligatoriedad del cumplimiento de la futura Carta Pastoral.

Resulta, sin embargo, que los documentos publicados por y en nombre de una Conferencia episcopal, por eso $y$ como tales, tienen un aspecto adyacente: Ladquieren una fuerza mayor esas enseñanzas?

La pregunta y la respuesta se plantean a un nivel estrictamente teológico. Si se responde que sí, el problema está resuelto. Pero si se responde que no o que se trata de un problema no resuelto la interrogación queda abierta: que una conferencia episcopal no añade nada a la fuerza obligatoria de sus enseñanzas porque eclesiológicamente carece de estricta facultad docente $y$ es un problema no resuelto que habrá de seguir investigando a la luz de la doctrina del Vaticano II.

De todas formas, el documento poseerá fuerza obligatoria cuando se firme, por sus contenidos éticos y morales y por sus razones y argumentos teológicos. $Y$ más fuerza aún, porque los propios obispos firmantes no van a contradecirse diciendo que lo firmado en común como miembros de la Conferencia no lo respaldan como obispos singulares y concretos de sus respectivas diócesis. Sobre todo, porque no se trata de un obispo en solitario, sino de todo un grupo de obispos bastante numeroso. lo que, en buena lógica, no disminuirá, sino que aumentará la fuerza de la futura Carta Pastoral.

(5) La "Gaudium et Spes" en la más amplia totalidad del campo político y socioeconómico que trata, siguió con éxito la misma sistemática docente y pedagógica en sus dos partes, prólogo y epilogo. 
Esta dificultad valorativa surgió con motivo de la publicación de las cartas pastorales de diferentes conferencias acerca del desarme y de la paz entre las que los pareceres más encontrados, al menos en cuanto a los medios y formas, de empleo, se centraron en las de los obispos norteamericanos $y$ franceses.

Quizá por eso en esta ocasión se ha anticipado a matizar el problema - y con sus palabras previas cerramos este párrafo- el Presidente de la Conferencia Episcopal norteamericana en la apertura del último pleno del pasado noviembre. Dijo a este respecto el obispo J. W. Malone:

"La posibtidad de hablar corporativamente a nivel nacional tiene una importancia social reconocida muy a menudo por otras organizaciones religiosas y los mismos críticos de la lglesia. La sistemática organizativa catófica, reffejada en nuestra conferencia episcopal, une las raices locales con la estructura nacional de una forma que muy pocas instituciones pueden lograr. Quizá el ejemplo reciente más claro del impacto de esa combinación de la presencia local y nacional fue la carta pastoral "El desafio de la paz". Precisamente porque hablamos como conferencia en un tema que ha de decidirse a nivel nacional fuimos capaces de dirigimos a nuestra sociedad como conjunto. El interés nacional que despertó esa carta no sólo fue por lo que dijimos, sino por el camino elegido para decirlo. Dentro del marco de la Conferencia, por supuesto, pemanece firme la base teológica y ef espacio público para la voz de cada obispo particular y de cada grupo de obispos. Ciertamente que la misión docente de cada obispo particular la ha desarrollado con mayor plentud la teología católica que la mision de la Conferencia Episcopal. La interrelación de las voces episcopales singulares con la de la conferencia como un todo tiene que reforzarse mutuamente. Utilizando de nuevo la experiencia pastoral sobre la paz, los obispos individualmente prem pararon a sus diocesanos para esa carta con propios mensajes y exposiciones diocesanas. Cuando se ha establecido y expresado un consenso por una conferencia episcopal a nivel nacional, cada obispo dispone ya de un marco en el que articular las peculiares implicaciones y posturas de especificas particularidades y conclusiones. Creo que expreso la prevalente experiencia de los obispos al decir que la exposición de una conferencia sobre un punto particular nos abre a nosotros como tales obispos un lugar en la opinión pública muy distinto al que pudiera lograr la expresión aislada sobre el mismo parecer. La decisión de una conferencia provee también de base a cada obispo singular para proyectar a nivel local o regional el punto de vista concreto. Resumiendo: la conferencia no reemplaza la voz de cada obispo particular sino que les facilita marco en el que articular coherentemente una visión teológica, moral y social, así como el sentido direccional que la lglesia puede determinar. La Conferencia es una estructura única, eclesial y socialmente, para delinear un consenso acerca de las decisiones públicas y expresato." $(6)$.

Un poco larga ha sido la cita. Pero merecia la pena por su sinceridad, competencia, profundidad teológica e incluso por el aspecto disciplinar que sugiere dentro del propio colegio episcopal, así como para valorar, en su punto preciso, la fuerza doctrinal, moral y pastoral de la futura carta cuando y como se apruebe.

(6) Cfr. "New York Times", 13 de noviembre, (p. A 22) Excerpts from Speech to Bishops over their Role in Public Policy Arena. 


\section{Primeras y segundas reacciones}

A partir del siguiente día de la distribución pública reaccionaron los Medios de Comunicación Social, sobre todo los más relacionados con el mundo de la economía y la empresa o de los negocios. Han querido hacerlo, rápidamente al menos en forma provisional, ya que intuyen y valoran la importancia del documento. Lógico, porque en el fondo, y un poco más arriba también, se esta diciendo que la estructura económica de los EE. UU., si en si no es inmoral, al menos es injusta en sus frutos y, por lo tanto, desde este aspecto, resulta éticamente incalificable y hay que reestructurarla inyectándole una importante reforma algo más que accidental.

El material es abundantísimo y no queda otro remedio que el recurso a la antología y selección que intentamos hacer de la manera más objetiva y neutral posible. Porque tampoco cabe una síntesis debido a la gran apertura del abanico de pareceres que llega hasta la oposición de los $180^{\circ}$, cuando se dan posturas incondicionales a favor del proyecto, otras en contra y todo un amplio espectro intermedio matizado, más o menos cerca de uno de los extremos en el difícil intento por situarse equilibradamente en el medio.

Por eso la retahíla de algunos testimonios elocuentes entresacados de las primeras y segundas reacciones publicadas en EE. UU. $Y$, después, las lógicamente más escasas y menos profundas que hemos detectado en España.

\section{a) En Estados Unidos}

La prensá norteamericana y demás medios de comunicación social del mismo 13 de noviembre se volcó ya en editoriales y amplios reportajes acerca del proyecto pastoral. Destacable siempre, dentro de las críticas, algunas veces muy duras, el tono de profunda consideración y respeto. Seleccionamos dos diarios: Uno de la capital federal, donde se celebraba la plenaria, "The Washington Post", y otro de la metrópoli neoyorquina "The New York Times".

"The Washington Post", diario independiente, dedica al tema un editorial, una viñeta y cuatro extensos artículos (7). El editorial, Los Obispos y la Economía, acentúa estas ideas:

Los Obispos católicos, una vez más, se lanzan a un ardiente debate secular. La carta sigue la línea ordinatia del pensamiento judeo-cristiano en favor de los pobres. Un sector de empresarios católicos y otros prominentes seglares se encuentran molestos por el esperado tono anticapitalista del borrador.. mientras que el mismo Michael Novak (cfr. más abajo) ve el proyecto más como plataforma de un partido político que como documento moral. El tono es quejumbroso como resulta habitual. El acento en la distribución más justa puede hacer que el mayor crecimiento logrado por el capi-

(7) Cfr. pp. A 1, A 4 y A 14. Téngase en cuenta que el tamaĥo de las páginas es el conocido en el argot periodístico como "sábana". El editorial se titula "The Bishops and the Economy"; en la viñeta aparece la caticatura del presidente Reagan leyendo la Carta de los Obispos (Bishops' Letter) con la siguiente leyenda: "Ayudar a los pobres, pero Lqué clase de religión es ésa?" 
talismo se vuelva contra los mismos pobres. Aunque un fuerte crecimiento económico no tiene por qué ser necesariamente incompatible con una distrubución de rentas más equitativa. Los obispos subrayan una serie de puntos que son parte del programa liberal. Pero el borrador resulta más capitalista que anteriores documentos sociales de la Iglesia Católica. Es destacable la insistencia en la justa retribución salarial pero guardando el equilibrio y sin perjuicio de la iniciativa privada ni del bien común.

Por lo demás el editorial se mantiene en una postura aséptica después del análisis que hemos resumido.

El primero de los cuatro artículos: El Presidente de los Obispos norteamericanos brinda la colaboración de la lglesia para remodelar la politica económica. Callarse sería incumplir el deber católico (8) recoge los puntos más importantes del discurso del Presidente de la Conferencia y unas declaraciones del nuncio Pío LAGHI.

El segundo artículo, con titular a toda página Los obispos resucitan proyectos abandonados por impracticables y demasiado costosos (9), critica las recomendaciones del borrador como superadas por la experimentación negativa al no haber tenido éxito en el pasado. Ciertamente que en el fin de ayudar a los pobres todo el mundo está de acuerdo, pero surge la discrepancia en cuanto a los medios y caminos tanto en economistas como en políticos dado el comportamiento y la naturaleza de las instituciones sociales y económicas norteamericanas:

No se ve económicamente cómo hacer descender el paro sin inflación; mejor que la progresividad fiscal bajar el porcentaje tributario para no desan nimar al ahorro ni a la inversión; la ayuda a los paises en vías de desarrollo es impopular y ha fracasado: sus usufructuarios están paralizados intelectual y políticamente; en cuanto a la elevación de salarios ya se sabe que no hay paz entre salario mínimo e inflación...

E tercer artículo del "Washington Post": Prominentes demócratas dan la bienvenida al llamamiento para prestar una ayuda mayor a los pobres. Algunos afirman que la propuesta de los obispos no es realística (10), recoge una decena de testimonios facilitados preferentemente por varios miembros demócratas del Congreso que dan la bienvenida al borrador. Las principales críticas o deseos recogidos son:

Esperemos a ver si el documento sacude la conciencia de los políticos. Puede ser un catalizadó para que los que viven y actúan como si la pobreza no existiese, reexaminen el problema. El déficit de 180 billones (norteamericanos) en el presupuesto federal impedirá hacer nuevos progresos en la lucha contra la pobreza y/o el paro estructural. Esperemos a ver en qué queda todo al final del debate de un año de duración y que no ha hecho más que comenzar. Sin duda que el documento tendrá una significación política grande. Pero ¿por qué no se distribuyó antes del 6 de noviembre pretex-

(8) MARJORIE HYER, Head of U. S. Bishops pledges Church Effort to shape Policy. Silence called dereliction of Catholic Duty. Cfr. pp. A I y A 4.

(9) JOHN BERRY, Bishops revive Proposals abandoned as unworkable, too costly. Cfr. p. A 4 .

(10) HOWARD KURTZ, Democrats on Hill welcome call to give Poor more Assistance. Some say Bishops' Proposal unrealistic. (p. A 4). 
tando neutralidad en el perfodo electoral y sí se habló del aborto, que impactó la campaña política? ¿Por qué no se levantó el "secuestro" del borradof? Hubiera producido un tremendo impacto.

El último de los cuatro artículos, Los Obispos y el Pobre (11), es aún más llamativo porque su autor fue vicepresidente de la Comisión Seglar para la Enseñanza Social Católica y la Economía Norteamericana. El artículo es, aunque abierto a la esperanza, crítico-negativo. Damos a continuación un amplio resumen de sus ideas y afirmaciones:

De llevarse a la práctica lo que propone el borrador, el Gobierno necesitaria nuevos $y$ aplastantes poderes para determinar comparativamente salarios-productividad; elevar el salario minimo por encima del nivel de pobreza; limitar los ingresos personales, así como la riqueza personal o tamiliar; señalar niveles de bienestar social por ley federal y no por leyes de cada Estado o locales. El borrador se mantiene en la línea de la doctrina tradicional. Pero es tendencioso de alguna forma al respaldar sin más matizaciones los "derechos económicos" de las Naciones Unidas; muestra un marco preferencial en favor de los pobres desde un punto de vista retrospectivo. Dice el proyecto que es antiestatista por principio y que el estatismo es peligroso, pero, en la práctica, el documento se muestra estatista sin vergüenza. La sección de la Sagrada Escritura que se ofrece como textoprueba para justificar, por ejemplo, el eslogan corriente de la "opción preferencial por los pobres" simplifica extraordinariamente el significado de pobreza y pobres en la misma Biblia y a lo largo de la historia. El documento falla desagradecidamente hacia los emigrantes-fundadores de la Union que impulsaron el movimiento económico más original de la histora para el crecimiento económico. ¿Cómo serían los EE. UU. si se hubieran fundado sólo sobre los principios del pensamiento social católico de 1776 ? ¿Otro Salva* dor? ¿Otro Brasil? Y también es desagradecido para con la oportunidad que los católicos norteamericanos han tenido de participar en tan original experimento sin el que nunca hubieran podido aprender el camino de las liberta des religiosas, los derechos humanos, la libertad de prensa, el derecho a ta libre asociación sindical, a la retribución por encima de "salario vital", ni las libertades que dan lugar al dinamismo económico, al desarrollo y a la inventiva creadora... No consideran los obispos que desde 1970 se han creado 27 millones de puestos de trabajo, mientras que en Europa se perdieron dos. Parece que los obispos pretenden encaminar el país a un nuevo consenso, pero ino es eso misión de los dirigentes politicos? porque los obispos son maestros morales y no dirigentes políticos. El borrador emplea, sin matices, ni clarificaciones, expresiones de socialistas europeos como "democracia económica" (Olof Palme) y "derechos económicos" (ONU): Lrespaldan esas concepciones? Siempre fustigan, en primer lugar, al pueblo norteamericano como los demócratas en $\mathrm{S}$. Francisco. Los obispos encuentran moralmente inaceptable la distribución de la riqueza en los EE. UU. pero dla comparan con las otras 165 naciones actuales?

Hemos de permanecer a la espera para verla importancia y la eficacia que se otorgará a estas y similares acotaciones comparando el segundo borrador con este primero que ahora nos ocupa.

Pasando ya al otro diario seleccionado, "The New York Times", nos encontramos con que también el mismo día 13 de noviembre muestra un gran despliegue editorial-informativo sobre el borrador (12).

(11) MICHAEL NOVAK, The Bishoos and the Poor. I, c.

(12) Dedica "The New York Times" un editorial firmado por KENNETH A. BRIGGS con el 
El autor del editorial, con el título Los obispos católicos urgen cohesión en sus decisiones públicas, no se anda por las ramas y va, con mucho conocimiento de causa, a las raíces y problemas fundamentales como el pluralismo y la capacidad de magisterio de la Conferencia Epis. copal, siempre respaldándose y entrecomillando palabras del mismo presidente, arzobispo Malone. Entresacamos:

Los obispos católicos seguirắn esforzándose por encauzar la Conferencia en las orientaciones que deben impregnar las decisiones públicas. Se señala el enérgico alegato de Malone en pro de la cohesión - unidad-m dentro del ancho espectro ("broad spectrum") posible dentro de la Conferencia en temas como el aborto, armas nucleares, derechos humanos y pobreza, recogiendo que no se refería en concreto a ningún obispo en particular. La Conferencia no quiere - ino puede? - reemplazar la voz singular de ningún obispo (13). Se recoge que es preferible la integración de opciones ("array of issues") si bien en un traje o túnica sin costuras, inconsútil ("seamless garment" frase acuñada por la posición de Bernardin) que una sola opción (O'Connor y Law). La lógica más profunda de los principios de la moral católica ha enseñado a los obispos a unir distintas opciones más que a marginarlas. El desafío de la opinión pública con el que ahora nos enfrentamos es diferente al del tema del aborto (al que nos oponemos totalmente) $y$ al del mismo tema nuclear, distinguiendo entre mentalidad, ambiente (constituency) y policy (decisión polf́tica).

Este editorial merecería una transcripción íntegra y ya que no puede hacerse en este lugar, quede la recomendación para intentar su lectura cuando se presente la ocasión.

En segundo lugar "The New York Times" transcribe una selección muy amplia del discurso inaugural de la Plenaria. No nos extendemos más en este punto porque nos hemos referido a él junto con el editorialista y al hablar del "Valor doctrinal" de los documentos emanados de las Conferencias Episcopales.

En tercer lugar, el artículo Aplicando la tradición Romano-Católica a la Economia de los EE. UU. Para el articulista el trabajo de 120 páginas es un primer intento comprensivo de aplicación de la Biblia, Teología y documentos papales a la actual economía de los EE. UU. Constituirá, sin duda, una de las intervenciones más importantes de la jerarquía católica norteamericana. La postura de SCIOLINO destaca, además, puntos como:

La necesidad de que ciertos temas deban considerarse desde una perspectiva católica. Recordar los excesos del capitalismo como recientemente Juan Pablo ll en Canadá. Repescar (católicamente) la economía en colaboración con los numerosos agentes que intervienen en ella. El articulista prevé que el documento alcanzará más difusión y tendrá más repercusiones que la misma Carta Pastoral sobre la paz. Le parece al articulista muy destacable la sugerencia episcopal de poderse dar una verdadera reevaluación de las estructuras y de la práctica del capitalismo norteamericano desde el

título Catholic Bishops urges cohesion on public issues; media página m- tamaño "sábana"- a seis columnas, al discurso de apertuka del presidente también de la Conferencia al que ya hemos aludido (cfr, nota 7); y otro tercio de página por ELAINE SOCIOLINO rotulada Applying fioman Catholic Tradition to U. S. Economy. Cfr. pp A 1, A 22 y A 23.

(13) A este punto nos hemos feferido antes más ampliamente en el apartado Valor doctrinal del documento; cfr. el 1. c. en la nota (7). 
punto de vista ético. El borrador continúa la línea comenzada por León Xill y demás intervenciones sociales católicas. Pero tampoco es de extrañar el elogio que hace del provecto la comunidad judia notteamericana.

La aportación del "The New York Times" en cuanto a primeras reacciones queda suficientemente patente el día 13 de noviembre con las tres muestras presentadas. No obstante, parece que el diario de Nueva York detectaba una laguna en su propia información: el parecer de los obispos, sobre todo la de aquellos que no tomaron parte ni tuvieron ninguna responsabilidad en la redacción del borrador. Y el día 15, el colaborador especial KENNETH A. BRIGGS insiste con una crónica $E I$ documento elogiado por el obispo PARLEY. La reacción está en pleno desarrollo ya y quiere hacerse constar que "los obispos católicos expresaron su entusiasmo en la primera intervención pública sobre el proyecto de la carta pastoral sobre la economía de la nación", aunque "desde su aparición en la misma Iglesia han surgido distintas voces que han comentado el contenido del borrador tanto positiva como negativamente. Trece obispos han presentado sus opiniones $y$, salvo escasas excepciones, los comentarios son muy favorables, to que indica que el borrador obtendrá con facilidad la aprobación episcopal. Las recomendaciones para la próxima redacción indican que se acentúe la nota de esperanza para equilibrar los rasgos negativos; mayor énfasis en cómo puedan aplicarse individualmente las exigencias morales por parte de los católicos y un estilo más inspirado.

Por otra parte se pide que no se caiga en el simplismo ante problemas tan complicados; que se busque el equilibrio entre el individualismo y la solidaridad social; nada de paralizaciones; pasos concretos especialmente para los católicos que han disfrutado de gran prosperidad en las últimas décadas, porque tienen la responsabilidad de atender a las necesidades de los pobres; qué pasos dar para reducir el foso entre pobres y ricos; desproporción entre grandes exigencias al Gobierno con las menores que se piden a los particulares; añadir un elemento más de esperanza cristiana para balancear el tono negativo y que el documento entusiasme más vitalmente como otra Novena Sinfonía; que quede más claro lo que el documento representa para los distintos tipos de católicos: "un ejecutivo, una madre que monta circuitos integrales o un trabajador agrícola".

Después de la precedente cala en dos diarios haremos lo mismo con un par de revistas caracterizadas: "Internacional Business Week" de la semana del 12 de noviembre y "Time" del 26 del mismo mes.

"International Business Week", la conocida revista financiera y empresarial, titula desde su portada: La lglesia y e/ Capitalismo. El documento de los Obispos Católicos sobre la economía de los EE. UU... levantará polémicas (14). Los centros más destacables de atención los centra en las siguientes ideas:

(14) The Church and Capitalism. A Report by Catholic Bishops on the U. S. Economy will cause Furor. El tema de la cubierta lo desarrolla la revista en sus pp. 54-56, muy densas de contenido. El reportaje no tiene firma sino que lo asume la propia revista. Subtítulos: "Peso moral", "Desconocimiento", "Tensiones", "Fuerte impresión", "Libres para disentir" $y^{\text {"Sin especiales }}$ reproches" ${ }^{\prime \prime}$. Todo el texto es de una objetividad ejemplar. Salvo error tu omisión se hacen desfi- 
El documento contrasta la enseñanza social y la doctrina moral católica con el comportamiento práctico, ejercicio al que no están acostumbrados la mayoría de los norteamericanos incluidos los católicos. El documento levantará una gran polvareda. Expone lo que los obispos creen política económica injusta, especialmente con los pobres de aquí (EE. UU.) y del Tercer Mundo. Se muestran más liberales (abiertos, progresistas) que conservadores. Fuertemente críticos con la Administración Reagan.

Es de lamentar que los obispos hayan comprometido su prestigio y autoridad moral en pro de una mayor intervención social en el sector privado. No ven que intervenir en la economía privada impide la creación de nueva riqueza y un beneficio a mayor número de gente, que la acción gubernamental directa. Se confunde en el documento el capitalismo europeo, que asume una sociedad estática, con el capitalismo democrático norteamericano, muy dinámico.

El capitalismo que bosqueja el documento no es el capitalismo que tenemos en EE. UU. No se contempla el capitalismo sólo, sino el conjunto de la economía de los EE. UU. No va a haber confrontación sino tan sólo diferencia de opiniones dentro de la libertad para discrepar, sin especiales reproches o censuras. Hay una tendencia hacia el capitalismo (en Europa, en China continental, etc.). LOlvidan los obispos este signo de los tiempos? Se aportan nuevos testimonios de obispos, economistas, etc., entre los que destaca el del Rey. Richard John NEUHAUS, ministro luterano y autor del libro The Naked Public Square sobre relaciones Iglesia-Estado, que afirma: "La Iglesia Católica se encuentra ahora en óptima posición para ejercer la más fuerte influencia con el fin de infundir una perspectiva retigiosa en las cuestiones públicas. Cómo ha de usarse esa influencia es el vértice de la argumentación entre los obispos y sus críticos."

No menos elocuentes y aleccionadoras son las enseñanzas de la revista "Time" en su reportaje: ¿Acaso soy yo el guardián de mi hermano? (15)

\section{A continuación las ideas más destacadas:}

Documento largamente esperado y altamente contestado. Positivamente recoge la gran capacidad de cabalgada que tiene la economía de los EE. UU. y negativamente los grandes fallos, masivos y ciegos, moralmente injustificables. Se trata de un llamamiento a la generosidad y a la buena voluntad. Es.la incursión más dramática en los asuntos públicos junto con la pastoral sobre la guerra y el desarme. No puede darse discrepancia en el

lar dieciocho nombres y pareceres de todo tipo que hemos pretendido recoger sintéticamente en el cuerpo de este artículo, lamentando no poder citar nombres ni actividades. Destacamos el del luterano NEUHAUS y al del jesuita HOLLENBACH como novedad. El espacio nos impide otra cosa, pero no queremos dejar la mención entrefiletes como "Estamos intentando completar el trabajo de los obispos. No decimos que Dios sea republicano" (W. E. Simon): "Sila cuestión es cómo ayudar a los pobres... ế capitalismo está hecho para responder a esa pregunta" (M. Novak): "Los obispos como economistas ¿infravaloran el daño de la intervanción gubernamental?"; "Tememos que el documento se convierta en un partido de fútbol político"; etcétera.

(15) Am / my Brother's Keeper? A Letter by Catholic Bishops on U. S. Capitalism whips up a Storm of Controversy (pp. 56-58). Estas densas páginas están firmadas por JOHN GREENWALD, JAMES CASTELLY (Washington) y J. MADELEINE NASH (Chicago). Desfilan conocidos $y$ nuevos testimonios (veintitrés en total, s.e. u.o.) equilibradamente progresistas $y$ conservadores tanto ideológica como económica o empresarialmente. Un recuadro Weakland at the Keyboard sobre la vida, extraccion social y curficulum del presidente de la Conferencia Episcopal con algunas afirmaciones muy características completan la información de "Time". 


\begin{abstract}
básico objetivo moral. Es incierta la influencia o impacto que producirá la carta en el cada vez más independiente laicado católico. Muchos empresarios y políticos catðlicos habrán de contarse entre los desafiados por el borrador. Un grupo de católicos ofrecerán su propia "contra-carta". Porque las medidas que proponen los obispos se han mostrado experimentalmente como insuficientes. En el documento supuestamente antiestatista llama poderosamente la atención el marco estatista que propone. Se necesita un pastel más amplio no distribución distinta del que existe. Hemos arrojado (en EE. UU.) un trillón de dólares para remediar la pobreza y tenemos ahora más pobreza que nunca. Los liberales se felicitan por la llegada de la pastoral: las ideas pueden no ser acomodadas a la moda politica, pero eso no quita peso moral a su argumentación. Los conservadores afirman que tiene poco que ofrecer y aplaudiendo los bienintencionados tines de los obispos fallarán las medidas o serán contraproducentes: inflación, paro.
\end{abstract}

La propia revista "Time" concluye que el documento puede tener en el pleno episcopal una aprobación más sueve y fácil que la pastoral sobre el desarme y la paz, aunque sólo sea porque se muestra más próximo a la enseñanza social católica ya aceptada. Pero podría ganar en mayor aceptación tanto dentro como fuera de la lglesia si los obispos atendieran la crítica que les indica que algunas de sus prescripciones económicas están superadas, desfasadas, pasadas de moda.

Con la selección precedente ponemos punto final a las primeras $y$ segundas reacciones del primer borrador en los propios Estados Unidos y pasamos a analizar las mismas en España.

\title{
b) En España
}

Era de esperar, lógicamente, que las resonancias del borrador norteamericano fueran mucho menores en España por varias razones: tardanza en conocer el texto íntegro del borrador, errónea creencia de tratarse de problemas típicos y exclusivos de los EE. UU. y, sobre todo, la indiferencia que se detecta ante la problemática de la ética social a pesar de las situaciones concretas de crisis en que vivimos, que no logran hacer vibrar las conciencias individuales, ni tampoco las de sectores económicos como los sindicales, empresariales, políticos y, mucho menos, las de los gestores del bien común para poner en práctica una orientación medianamente aceptable (16).

Seguimos semejante metodología que en el apartado anterior: unos botones de muestra tanto de la prensa diaria como de un par de revistas que se han preocupado con mayor inmediatez del tema.

La prensa diaria ofrece y se preocupa por la noticia en apretadas reseñas objetivas y exactas. Sin embargo, los titulares, como no podía ser menos, se muentran parciales.

Titula "ABC" del 13 de noviembre: "Los obispos U.S.A. piden mayor protagonismo al Gobierno en política económica" y debajo selecciona las siguientes ideas:

(16) Esta penosa realidad se ha podido constatar con motivo de la publicación de la reciente Declaración de la Comisión Episcopal de Pastoral Social Crisis económica y respon. sabilidad moral. 
El borrador tiene ya un aire tan marcado que podrá suavizarse pero no cambiarse. Los obispos adoptan inequivocamente la postura de que... el Gobierno debe interpretar un papel mucho más importante... La idea de los economistas es que los males económicos no se resuelven... sino dejando el protagonismo a la iniciativa privada, mucho más dinámica y efectiva. E nivel de desigualdad debe considerarse moralmente inaceptable. Proponen justo lo contrario que Reagan viene predicando y practicando... Aunque algunos dicen que (los obispos) tratan tan sólo de equilibrar su conservadurismo en el tema de las costumbres con un progresismo en ef tema economico, la tesis general es que creen lo que dicen y consideran un deber proclamario en defensa de los pobres... Con la receta que proponen, dicen los expertos, se puede terminar haciendo más mal que bien a los pobres... se desfonda la economía... Por eso un grupo de católicos influyentes (Haig. Simon...) han publicado una contrampastoral que reconoce el celo de los obispos, pero sostiene que el capitalismo es la mejor vía para ayudar a los pobres.

"Diario 16" del día 12 de noviembre adelanta la noticia con el titular: "Los obispos católicos contra la política económica del reelegido presidente U.S.A.":

Criterios más próximos al programa del derrotado Mondale que a las tesis def victorioso Reagan. Opción preferencial por los pobres y el papel del Gobierno. Las ideas se asemejan más al socialismo que al capitalismo de libre mercado que, según dicen, ha dado a EE. UU. su fuerza y riqueza.

El diario "Ya" del 13, a cuatro columnas, da la noticia y la información del entorno y del mismo borrador. Destaca, por las citas y referencias del corresponsal, por ejemplo, al "Business Week", los datos y exactos detalles, un notable conocimiento de causa. Nosotros conocemos ya directamente las referencias por las partes anteriores. Sólo indicar que las cobija el diario bajo el titular: "Los obispos norteamericanos consideran 'un escándalo' el índice de pobreza en EE. UU."

"Ya" en su referencia se ciñe a escogidas citas del borrador, salvo la indicación en determinado momento que también afirma: "postura (la de los obispos) que evidentemente choca con la filosofia general de la Administración Reagan".

Además de esa crónica, "Ya" publica el mismo día un pequeño editorial construido sobre la relación con otros documentos del episcopado norteamericano más recientes: "Marxismo y comunismo", "La asistencia sanitaria en los EE. UU.", "La presencia de los hispanos en los EE. UU.", "Aborto" y "El desafío de la paz" (contra la guerra nuclear y carrera de armamentos).

Como revistas hemos seleccionado "Ecclesia" y "Vida Nueva". En primera y segunda instancia no ha habido otras que se hayan hecho eco del borrador del episcopado norteamericano.

"Ecclesia" se ocupa en dos números (17): en el primero con el título firmado por E. GARCIA DIAZ, Los obispos norteamericanos denuncian la

(17) Cfr. n.० 2.198 del 2-X|-84, p. 1.439 y n. 2.200 del 8 XXI1-84, p. 1.503. 
injusticia económica, se ofrecen datos cronológicos y redaccionales, así como algunas insistencias propias como las que siguen:

La jerarquia se pronuncia a favor de una democracia económica. La nación norteamericana puede sentirse orgullosa de muchos de sus logros económicos, pero al mismo tiempo existen fallos masivos y repulsivos. Los obipos hacen una serie de recomendaciones que chocan con la política económica del Gobierno.

Se critican las discriminaciones que sufren las minorías y las mujeres y, severamente, la política norteamericana hacia el Tercer Mundo. Se puede afirmar que el documento va a provocar una polémica apasionante. Un grupo de personalidades católicas y de signo consenvador... defiende los méritos del capitalismo y ha redactado un contra-documento. Es solio el principio. El borrador no puede pasar desapercibido, sobre todo al poner el dedo en la llaga: la economia norteamericana, fuente de un grave escándalo moral.

La segunda vez "Ecclesia" interviene por la pluma de D. A. SANTAMARIA con el título La lglesia norteamericana estudia la economía del país recogiendo ya el eco de algunas opiniones:

La Iglesia Católica... tiene ahora el respeto de la opinión pública. Desde los grandes diarios hasta las emisoras de radio, han empezado ya el debate público sobre la economía, según deseaban los obispos. Se ha presentado un tema que hasta ahora nadie había tenido la osadía de exponer en público y desde una plataforma verdaderamente nacional. Economistas de la talla de Kenneth Galbraith han hablado... especiamente desde Harvard y otros centros econórnicos del país, de la necesidad de reformar ciertos aspectos de la economía de los EE. UU. con el fin de favorecer a los menos afortunados. Por el contrario, un grupo de católicos (BUCKLEY y NOVAK entre otros) se opone a la pastoral porque es un peligroso ataque al sistema capitalista: parece un documento socialista europeo. Pero la mayoría de quienes se ocupan de economía están tomando muy en serio el documento episcopal. La reforma que piden los obispos es económica, pero está inspirada por los imperativos del evangello que defienden la dignidad de todo ser humano. Que Norteamérica recuerde sus raíces inmigrantes y sepa abrir las puertas y la movilidad social a los grupos que están en "pobreza endémica", como los negros y los hispanos.

Los obispos quieren influir en la política económica del país es el título de la referencia de "Vida Nueva" firmado por Mary G. SANTA EULALIA (18). Se afirma allí que el borrador se esperaba con gran tensión y recuerda "Vida Nueva" más adelante:

Parece que no existe el ataque que algunos temían contra la política de Reagan en el ámbito de la economía: la recomendación de una "unilateral desinversión" según el irónico lenguaje de "Wall Street Journal". Se hace una revisión de la postura bíblica y, según los comentaristas, se sacan en concreto conclusiones de corte liberal. Se hace causa por una democracia económica $\psi$, subrayando las enseñanzas de los Papas, se rechazan al mismo tiempo el control del estado socialista y el capitalismo desbocado.

(18) Cfr. n. 1.455 de $1-X \mid 1-1984$, p. $34 \mathrm{~s}$ 


\section{Conclusión}

En el camino que aún le queda por recorrer al borrador episcopal norteamericano es muy posible que se limen aristas, pero también que se enriquezca abundantemente. En cualquier caso la Carta Pastoral que surja en este $X X$ aniversario del Concilio Vaticano II se muestra como fruto maduro del mismo y, más en concreto, de la Constitución Pastoral "Gaudium et Spes" sobre el mundo moderno.

Por eso, por nuestra parte, nos comprometemos al seguimiento de los diversos hitos señalados y de los avatares que se produzcan así como del análisis comparativo de los tres borradores y de la opción final que se apruebe en noviembre. 